\title{
Determination of the road surfaces stress-strain state by using of Global Navigation Satellite System
}

\author{
Vitaly Baranchik ${ }^{1}$ and Anatoly Dotsenko, ${ }^{2, *}$ \\ ${ }^{1}$ Udmurt State University, Izhevsk, ul. University-1, Russia \\ ${ }^{2}$ Moscow Automobile and Road Constraction State Technical University, Moscow, Leningradsky pr., \\ 64, Russia
}

\begin{abstract}
The reduction of the current road repair costs is possible to be ensured by reducing its labour intensity and increasing interrepair periods. To achieve these goals, it is proposed to create a system of the road planned preventive maintenance (RPPM) based on the automated road stress-strain state diagnostics with constant measurement of the surface deformation by using the GLONASS and GPS navigation satellite systems operating in real time mode. The RPPM system will be based on the Global Navigation Network of permanently operating base stations, which allow to continuously monitor the dynamics of changes in the stress-strain state of roads and effectively plan any repair works thereupon. A preliminary economic analysis showed that by using of permanent geonavigation base stations the road repair costs will be annually reduced by $18.57 \%$ for the first five years, and then by half in the following two years. In this case, the payback period will be 5.4 years. In order to adapt the existing geo-navigation control systems of road building machines to the Solution of the problem of road repairing it is necessary to make an appropriate experimental and design engineering development. The use of satellite measurements in the diagnosis of road conditions is the basis of the system of preventive maintenance in the road sector and the stage of development of the domestic intelligent transport system.
\end{abstract}

\section{Theoretical and practical background}

For the reconstruction of existing and construction of new roads without an increase in funding, it is important to reduce their current repair and normative state maintenance cost components.

The "Safe and high-quality roads" national project's implementation cost analysis shows that the project's goal - to make $80 \%$ of all the national roads corresponding to standards by 2026 - can be achieved only through a radical change in repair planning to be based on the full utilization of the road resource with the consequent workscope reduction. This is possible only with the use of a preventive repair system, which is now absent in the road sector.

\footnotetext{
Corresponding author: dotsenko_ant@mail.ru
} 
Funds allocated to this national project are spent only on running repairs, as due to the backward diagnostics and low-quality surface repair the restoration intensity does not actually exceed the intensity of the surface destruction, which does not promotes the decrease in the volume of annual repair works, and over the long term the reconstruction and new construction will require additional funding.

The reduction of the current repair costs without an increase in funding is possible by reducing the labour intensity and increasing interrepair periods. To achieve these goals, it is necessary to create a system of the road planned preventive maintenance (RPPM) based on the automated road stress-strain state (SSS) diagnostics with the round-the-clock measurement of the surface deformation by the satellite signals of the GLONASS and GPS systems operating in real time mode (RTK). Modern methods for the evaluation of soil cyclic strength while processing the satellite measurement results are also planned to be used.

The information about the areas with SSS close to the limit value can be taken as the basis for the RPPM system.

Thus, the SSS value determination through the use of satellite measurements is an essential part of the RPPM system creation.

Modern outlooks on the mechanics of material destruction (fracture mechanics) are based on the initial existence of technological defects in the product material structure (dislocations, vacancies, micropores, foreign inclusions, temperature gradients, imperfection of surface layers), the destructive influence of which is intensely appeared in places of local stresses (surface dents and projections, places of cross-section change, manhole and curb joints, and other cuts) concentration (increase) [1].

Under cyclic loads, overloads, low or high temperatures, the presence of corrosive media and water, as well as during long-term operation, microdamages accumulate in the material, and then the number of defects increases and a lot of microcracks are formed. Adjacent microcracks unite together in a main crack, and the last ones form the main cracks pattern, which develops and comes to the surface in the form of macrocracks. Under the impact of newly arriving foreign aggressive inclusions (for example, periodically freezing and thawing water-salt-sand mixture), the macrocracks open up and, at a certain critical length, form a volumetric destruction of the surface. It should be noted that the crack development rate in material with a homogeneous structure may be very small, suggesting a safe crack length $[2,3]$.

Thus, it is important to prevent the water ingress under the road surface and thereby increase the road resource (time between repairs). This is possible due to the timely detection of the boundary stress state, provision of sufficient road-bed crossfall and the storm water drain organization. The Penetration of water under the coating is the main reason for reducing the strength of the pavement and the accelerated development of the main crack. The initial deformation of the pavement in the form of a track has a limit above which the crack comes to the surface and begins the intensive destruction of the coating and all the pavement. It is important to fix the time of the onset of extreme deformation of the pavement. In that regard, the actual problem is the RPPM system creation, based on the continuous roadnet stress-strain state monitoring and the timely minimum volume repair measures.

\section{Diagnostics of the stress-strain state of the road}

There Is an unambiguous relationship between the stress at uniaxial compression of soils and rocks in cramped conditions of varying degrees, and their deformation [8]. The existence of such a connection is proved by research A. N. Zelensky on a variety of brittle plastic materials. The results of these studies are the basis for the design of managed 
working bodies of construction, road and mining machines. In our case, the station database must contain the ultimate deformation of the coating corresponding to the tensile strength of the clothing for a given area with a given margin of safety.

Determination of a road section that is in a stressful state close to the limit, but without cracks on its surface, is possible only with the round-the-clock stress increase monitoring and signaling about the road section limit condition. In this case, the volume of repairs is drastically reduced and limited only to applying to the surface of a potentially dangerous section a thin layer of mastic filler and guss asphalt, which reduces labor intensity and costs by at least 2 times. At the same time, the overhaul period (resource) increases.

Currently, the road stress-strain state (SSS) diagnosis is performed by scanning the height of the road surface irregularities in three ways: by means of a straight-edge, ultrasonic method or it can be made by a perturbed vertical heaving oscillation of a car [4].

On the basis of the conducted studies [6] the mean square values of the ordinates of the microprofile of typical roads are determined. Cement and asphalt concrete coatings of good quality have the specified values, i.e. they can be considered normative. In all cases, the SSS is estimated by the root-mean-square height of the irregularities relative to the baseline corresponding to the cross slope of the road-bed. In the $60 \mathrm{~s}-70 \mathrm{~s}$ of the 20 th century, the root-mean-square values $q(\mathrm{~cm})$ of irregularities for roads with various wear degrees were determined [5], which were taken as the basis for the optimal design of vehicle's suspension:

Cement-concrete surface $0.8-1.26$;

Good quality asphalt $0.5-1.24$;

Cobbled surface of satisfactory quality 1.3-2.3;

Cobbled surface with bumps and depressions 2.5-3.3;

Broken dirt road 6-11.

The results of these works, considering the studies $[1,12]$ in the field of soil and road material cyclic strengths, can provide a background for creation of a scientific basis for the road planned preventive maintenance system. Thus, the following is proposed to be initial assumptions:

- The road surface is considered to be a random function of the only variable, the nonrandom characteristics of which are the dispersion and ordinates spectral density in the medial longitudinal cross section of the road bed, which, based on studies [14,19,20], are known for five types of roads [7].

- When in motion on a rough road, vehicle heaving oscillations depend only on the rootmean-square deviations (RMSD) of the microprofile ordinates and do not depend neither on the type of surface, nor its wear degree.

- The actual RMSD values equal to $0.5 \div 1.26 \mathrm{~cm}$, which are typical for the good quality asphalt and cement concrete pavements, can be considered as fully compliant with the quality regulatory requirements.

- When RMSD is equal to $1.3 \div 2.3 \mathrm{~cm}$ (satisfactory quality), an additional road section survey is required by using destructive control methods and determining stress concentration zones.

The RMSD of the road microprofile ordinates are statistically related to the traffic flow speed. This results from the following considerations. In the absence of speed limits, the average speed of a single car in motion on a specific road depends on its weight-carrying capacity, suspension parameters and the surface condition. The driver is limiting speed instinctively to conform to safety conditions and the vehicle and load sprung weight vibratory acceleration.

When driving in a traffic flow, the average vehicle speed decreases and, all other things being equal, depends on the vehicle parameters: weight-carrying capacity, engine power, suspension parameters, as well as the time of day and day of the week. It should be noted 
that, with a constant RMSD of the microprofile, the average speed change is cyclically occurring.

So, the current values of the vehicle's speed and vertical movement, measured simultaneously, can describe the current state of the road surface (RMSD of the microprofile) without resort to time-consuming measurements of the road microprofile. Previously, this method did not widely used due to the lack of tacheometers with millimeter measuring accuracy and automated vibration measuring systems in the 60s. Currently, such equipment is commercially available.

The diagnosable road monitoring results will be recorded for a day, week, month, year, resulting in the information database creation, which will be stored and processed in a computer until the RMSD of an average vehicle reaches the admissible limit value corresponding to the road section surface ultimate strength. Around-the-clock navigation measurements are possible only when using permanent base stations (PBS), which are stationary mounted and ensure the operation of an unlimited number of the Global Navigation Satellite System (GNSS) receivers in their coverage area.

Assume that as a result of continuous monitoring, i.e. continuous observation of the car speed and vertical oscillations, the $q$ change dynamics, i.e. deformation of the road pavement surface, is determined, and at some instant the $q$ value reaches its limit. This moment will be a signal of the need to repair this section of the road. Delay in the start of repair means an increase in the amount of works and additional costs. As $q$ admissible values you may use the above values or data from laboratory study [17].

Figure 1 shows measurements of white roads with the help of Reiki and a basic straight according to ONE 218.0.006-2002, not a design scheme.

According to ONE, the evenness of the road is determined in the transverse direction by means of a rail 3 meters long and a base line inclined to the horizontal at an angle of 1 degree, taken as the beginning of the reference, as well as by the geodetic method.

Therefore, in figure 1: $l_{\max }=3 \mathrm{~m}(10$ points in increments of $\Delta \mathrm{x}=30 \mathrm{~cm})$. With a band width of 9 meters 3 -meter rail profile is measured at 30 points.

Experiments of the $70 \mathrm{~s}$ were carried out at $l_{\max }=8-25 \mathrm{~m}$, the length of the measured area $L=n l_{\max }=50-600 \mathrm{~m}, \Delta x=0.1-1.0 \mathrm{~m}$.

In the spectral theory of vehicle suspension, the road surface is considered as a nonstationary random function of one variable, so its statistical characteristic is the correlation function or spectral density of the microprofile ordinates.

The study of General patterns in the probabilistic characteristics of white road [6] showed that regardless of the method of measurement of roughness, the root mean square of their height with the length of the smoothing 8-25 meters, can be completely defined using a dimensionless constant characterizes the type and deterioration of white [5, p. 32]. Length $l_{\max }$ for nonstationary smoothing function of the stationary random white-in determines the maximum wavelength of the frequency component of the road to be considered in the white. With the increase of $l_{\max }$ increases the variance due to the accounting in the white waves of great length. The sampling value $\Delta \mathrm{x}$ determines the minimum wavelength of the frequency component taken into account in the microprofile, and the length of the section - the reliability of the results.

In the figure, the values $q_{1}, q_{2}, \ldots, q_{10}$ are the vertical deformations of the microprofile at points $1,2, \ldots, 10$, evenly spaced across the width of the road-bed at intervals $\Delta x=10 \mathrm{~cm}$. Axis $\mathrm{x}_{1}$ is a baseline inclined to the horizontal $\mathrm{x}$, forming a cross slope of the road-bed; $\mathrm{q}_{10}$ is the maximum surface deformation, which is compared with the admissible one that is lower than the main fracture stress value from the Permanent Base Stations Server database. 
Regardless of the road type, the measurement parameters choice is based on the following considerations. The larger is $q$ (the road is worse), the larger must be smoothing path $l_{\max }$ of the correlation function, so, in our case, $l_{\max }$ is equal to the width of the road. To improve the accuracy of the baseline plotting, the sample rate $\Delta x$ (of the point ordinates measurements) in the cross-section should be as small as possible, for example, $10 \mathrm{~cm}$. The length of the measured section L must correspond to the accuracy of the satellite measurement, depending on the distance to the base station, which should not exceed $25 \mathrm{~km} \mathrm{[6].}$

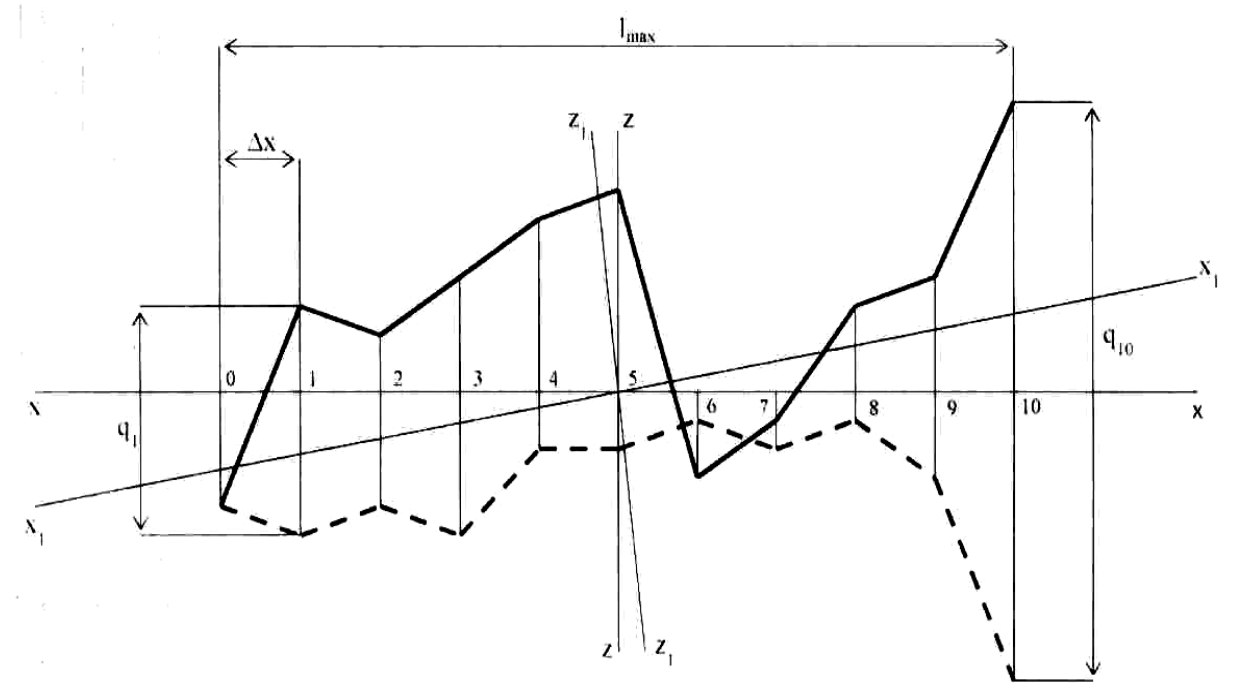

Fig. 1. .Microprofile deformation detection scheme:

(— before deformation; - — - - after deformation).

The cross slope angle and surface deformation permissible values stored in the Base Station Server database are determined from the core sample cyclic strength test results according to GOST 12248-2010 "Soils. Methods for determining the strength and strain characteristics"[7]. Samples should be selected at the extreme points of the traffic lanes with the minimum side reduction and strength [5].

Continuous monitoring of the surface deformations is possible only by means of Global Navigation Satellite Systems (GNSS). Such systems are used as vehicle-borne equipment to control the operating tools of road-building machines [6, 7]. The equipment requirements are determined by GOST R 57186-2016 "Intelligent Transport Systems. Road state accounting and monitoring system. Purpose, composition and characteristics of the vehicleborne navigation and communication equipment for road-building machines", developed by the Moscow Automobile and Road Construction State Technical University (MADI).

The vehicle-borne navigation and communication equipment (VBNCE) of a roadbuilding machine are the field base station rovers whose receiver works during the machine operation. Around-the-clock navigation measurements are possible only when using permanent base stations (PBS), which are stationary mounted and ensure the operation of an unlimited number of GNSS receivers in their coverage area. In our case, GNSS rovers are microprofile points, and there is no need in GNSS receivers. The task of the machine operating tools control is replaced by a simpler task of RTK control. The measurement results are processed by PBS, which provides corrections for an unlimited number of RTK rovers in its coverage area. If the RTK rover is distant from the PBS for more than $25 \mathrm{~km}$, it leads to the loss of accuracy of the coordinates received. In our case, we can hope for the reduction of this restriction, since not six but only two coordinates (height and angle in the 
transverse plane) are measured, and the other 4 coordinates are considered known, which reduces the systematic error.

The PBS operational control can be carried out autonomously or, if there is the PBS network, remotely from the control center via secure communication lines. In the latter case, there are prerequisites for improving the accuracy of measurements.

Summarizing the existing positive experience of using GNSS to control the operating tools of road-building machines by means of field base stations, it can be concluded that the transition to the use of PBS for the road SSS diagnostics will not require significant software changes, since the control task is replaced by a simpler control and signaling task.

\section{Discussion}

The economic analysis of repair costs at the initial stage of the PBS operation shows that the PBS equipment at the estimated value of 4 million rubles and with a service radius of 30 $\mathrm{km}$, reduces repair expenses by $18.57 \%$. When using the PDBS network, the costs are reduced even more due to the service area overlapping. The PBS payback period is 5.4 years, after which the road repair costs will reduce by at least 2 times.

\section{Conclusions}

Based on the study, the following can be concluded:

1. The road surface planned preventive proactive (protective) repair at the critical stage of the fatigue damage accumulation before the formation of the macrocracks pattern allows reducing costs by more than 2 times by reducing the volume and quality of repair works, and free up funds for the reconstruction and new construction.

2. The road planned preventive maintenance system should be based on the Global Navigation Network of permanent base stations that allow you to continuously monitor the dynamics of changes in the stress-strain state of roads and effectively plan repair works.

3. In order to adapt the existing geo-navigation control systems of road building machines to the Solution of the problem of road repairing it is necessary to make an appropriate experimental and design engineering development. The use of satellite measurements in the diagnosis of road conditions is the basis of the system of preventive maintenance in the road sector and the stage of development of the domestic intelligent transport system.

\section{References}

1. V. P. Baranchik, M. F. Zakirov, K. A. Ivanov, N. A. J. Intel. syst. in prod. 2 28-31 (2014)

2. V. P. Baranchik, M. F. Zakirov, S. V. Sychugov Book of reports of the "Interstroymeh2018" Inter. Scien. and Tech. Conf. (Moscow: Moscow State University of Civil Engineering) 39-44 (2018)

3. V. I. Dobrovolsky Izhevsk: Publishing house of the Izhevsk State Technical University 136 (2007)

4. V. I. Dobrovolsky J. Ind. lab. 7 44-50 (2005)

5. A. I. Dotsenko J. Mech. of constr. 10(77) 5-9 (2016)

6. I. G. Parkhilovsky Proceedings of the NAMI seminar on car suspension systems, $15^{\text {th }}$ edition 22-48 (1966)

7. I. G. Parkhilovsky Moscow: Mechanical Engineering (Mashinostroenie) 232 (1978) 
8. I.T. Mirsayanov et al. Izvestiya KazGASU 3 58-62 (2014)

9. Catalog of ZAO "Geostroyizyskaniya": TOPCON building machinery control systems, $4^{\text {th }}$ edition.

10. A. V. Skvortsov, P. I. Pospelov, V. N. Boykov Moscow: Informavtodor 372 (2006)

11.Z M.F.akirov, V. P. Baranchik Book of reports of the "Interstroymeh 2012" International Scientific and Technical Conference (Izhevsk: Publishing house of the Izhevsk State Technical University) 80-83 (2012)

12. E. B. Mikhalenko St. Petersb: Publishing House of the St. Petersburg State Polytechnic University 79 (2009)

13. ODN 218.0.006-2002. Road Condition Estimation and Diagnostics Rules.

14. V. S. Krasikov, O. V. Trofimov Moscow: Mechanical Engineering (Mashinostroenie) l.6 235-247 (1975)

15. M. D. Ageev, N. D. Ageeva Proceedings of the seminar on car suspension systems (Moscow: NAMI) 1.8 17-39 (1963)

16. Ya. M. Pevzner Proceedings of NAMI,-Moscow: Publishing house of NAMI 1.66 3-23 (1964)

17. GOST 12248-2010. Soils. Methods for laboratory determination of the strength and deformability characteristics (Moscow: Standartinform)

18. A. A. Silayev Moscow: Mechanical Engineering (Mashinostroenie) 192. (1972)

19. H. Braun German study of the motor vehicles and road transport equipment driving $\mathbf{1 8 6}$ 1-82 (1966)

20. Van Deusen Bruce D. Analiitical Techniques for Designing Riding Quality into Automotive Vehicles SAE Preprints (1967) 